\title{
CURRÍCULO DES-OCULTO: outras vozes, outras epistemologias
}

\author{
Débora Cristina de Araujo' \\ Luís Thiago Freire Dantas²
}

\section{RESUMO}

A prática docente é, sem dúvida, um dos grandes gargalos para a não efetiva implementação da Lei 10.639/2003 na educação básica. E o currículo representa um dos principais agentes de tal imobilidade. Tomando como princípios a "decifração do conhecimento" e o "alfabetismo da diáspora" (KING, 1996), neste artigo propomos refletir sobre o currículo predominante na educação brasileira e discutir sobre práticas pedagógicas que protagonizem a Educação das Relações Étnico-Raciais. Tomamos como foco de investigação o ensino superior - por meio da análise do componente curricular da disciplina de Educação das Relações Étnico-Raciais (Erer) para os cursos de licenciatura de uma universidade federal - e no ensino médio, a disciplina de Filosofia em uma instituição estadual e outra federal. Nessas análises, incluem-se documentos oficiais e propostas de práticas pedagógicas desenvolvidas durante as aulas nos anos de 2016 e 2018. As contribuições almejadas são especialmente no sentido de desocultar o currículo e propor ações concretas para a valorização de princípios africanos e afro-brasileiros na formação docente.

Palavras-chave: Currículo. Educação das Relações Étnico-Raciais. Prática docente.

\section{CURRICULUM UNCOVER: other voices, other epistemologies}

\begin{abstract}
Teacher practice is undoubtedly one of the major bottlenecks for the non-effective implementation of Law No. 10.639/2003 in basic education, and the curriculum represents one of the main agents of such immobility. Taking as a principle the decoding of knowledge and the diaspora literacy (KING, 1996), in this article, we propose to reflect on the predominant curriculum in the Brazilian educational system, and to discuss pedagogical practices that lead to ethnic-racial relations education. We focus on higher education - through the analysis of the curricular component titled Ethnic-Racial Relations Education for the undergraduate courses of a federal

1 Doutora em Educação (UFPR). Professora da Universidade Federal do Espírito Santo, no Programa de Pós-Graduação de Mestrado Profissional em Educação e no Departamento de Teorias do Ensino e Práticas Educacionais (Centro de Educação), atuando na disciplina de Educação das Relações Étnico-Raciais. Orcid iD: https://orcid.org/0000-00018442-3366. E-mail: debora.c.araujo@ufes.br

2 Doutor em Filosofia pela Universidade Federal do Paraná. Pesquisador de filosofia africana, pensamento decolonial e ensino de Filosofia. Orcid iD: https://orcid.org/0000-0001-8524-8213. E-mail: fdthiago@gmail.com
\end{abstract}

Revista Exitus, Santarém/PA, Vol. 9, № 4, p. 147 - 175, Out/Dez 2019. 
university - and on high school - through the analysis of the Philosophy subject matter taught in a state institution and in a federal one. These analyses include official documents and proposals for pedagogical practices developed during the years 2016 and 2018. The desired contributions are especially aimed at unveiling the curriculum and proposing concrete actions for the valorization of African and AfroBrazilian principles in teacher education.

Keywords: Curriculum. Education of Ethnic-Racial Relations. Teacher practice.

\section{CURRÍCULUM DES-OCULTO: otras voces, otras epistemologías}

\section{RESUMEN}

La práctica docente es, sin duda alguna, uno de los grandes cuellos de botella para la no aplicación efectiva de la Ley 10.639 / 2003 en la educación básica. Y el currículum representa uno de los principales agentes de tal inmovilidad. Basados en principios de la descodificación del conocimiento y el "alfabetismo de la diáspora", proponemos en este artículo reflexionar sobre el currículum predominante en la educación brasileña y discutir sobre prácticas pedagógicas que destaquen la Educación de las Relaciones Étnico-Raciales. Enfocamos la investigación en la enseñanza superior - a través del análisis del componente curricular de la disciplina de Educación de las Relaciones Étnico-Raciales (Erer) para los cursos de licenciatura de una universidad federal - y en la enseñanza media la disciplina de Filosofía de una institución estadual y otra federal. En estos análisis incluimos documentos oficiales y propuestas de prácticas pedagógicas desarrolladas durante las clases en los años 2016 y 2018. Las contribuciones que anhelamos alcanzar son especialmente en el sentido de revelar el currículum y proponer acciones concretas para la valorización de principios africanos y afrobrasileños en la formación docente.

Palabras-clave: Currículo. Educación de las Relaciones Étnico-Raciales. Práctica docente.

\section{INTRODUÇÃO}

Ao compreender o espaço escolar como um microcosmo da sociedade, é pertinente que uma série de elementos que o compõe, como o currículo, por exemplo, expresse discursos legitimadores de determinadas vozes, evidenciando como o poder atua nestes campos. Para Teun A. van Dijk (2008, p. 117), os grupos e instituições dominantes exercem um "poder social", sintetizado pelo autor como "controle":

[...] os grupos possuem (maior ou menor) poder se forem capazes de exercer (maior ou menor) controle sobre os atos e as mentes dos (membros de) outros grupos. Essa habilidade pressupõe a existência de uma base de poder que permita um acesso privilegiado a

Revista Exitus, Santarém/PA, Vol. 9, № 4, p. 147 - 175, Out/Dez 2019. 
recursos sociais escassos, tais como a força, o dinheiro, o status, a fama, o conhecimento, a informação, a 'cultura' ou, na verdade, as várias formas públicas de comunicação e discurso (VAN DIJK, 2008, p. 117).

Mesmo não sendo um poder absoluto, os "grupos podem exercer maior ou menor controle sobre outros grupos ou apenas controlá-los em situações ou domínios sociais específicos" (VAN DIJK, 2008, p. 118). Entendemos que o currículo é um desses domínios, por classificar os grupos sem (ou com menos) poder, como "o Outro Conceitual", nas palavras de Joyce King (1996, p. 81).

Os Outros (dentre eles mulheres, pessoas com deficiência, grupos LGBT, povos indígenas e descendentes de africanos) são tomados no currículo como auxiliares para a produção de conhecimento. É pertinente, portanto, a indagação de Nilma Lino Gomes (2007, p. 24) sobre as narrativas do currículo: "São narrativas que fixam [esses] sujeitos e os movimentos sociais em noções estereotipadas ou realizam uma interpretação emancipatória dessas lutas e grupos sociais?". Ainda que seja retórica, uma possível resposta à pergunta parece ser sempre a mesma, diante dos currículos da educação básica e do ensino superior no Brasil: são narrativas que reproduzem estereotipias. À parte isso, a cada vez que a pergunta é feita, reações negativas também são manifestadas a ponto de classificar que "as recentes lutas das 'minorias' em torno do currículo e do livro didático representam apenas uma política de identidade equivocada, 'centrífuga' e causadora de divisões" (KING, 1996, p. 79). Ocorre uma espécie de punição a quem ousa denunciar o currículo.

Outra pergunta feita por Gomes aprofunda a discussão aqui pretendida: "Que grupos sociais e étnico/raciais têm sido historicamente representados de forma estereotipada e distorcida?" (GOMES, 2005, p. 24). É o que King (1996) também se debruça em sua análise. Ao epigrafar seu artigo com uma intensa afirmação de Vincent Harding (19743, p. 10 apud

\footnotetext{
3 HARDING, V. The vocation of the Black scholar and the struggles os of the Black Community. In: Institute for the Black World (Ed.). Educational and Black struggle: Notes from the colonized world. Harvard Education Review Monograph, 2, p. 3-39.
} 
KING, 1996, p. 75) - "Nossos ancestrais não atravessaram rios de sangue para que pudéssemos entregar a interpretação de suas vidas nas mãos de outros" - ela nos provoca ao exercício de "decifração do conhecimento": significa realizar uma operação intelectual diante do conhecimento e do currículo para decifrar narrativas e representações alienantes da história africana.

Ao omitir ou distorcer certos signos culturais, os relatos contidos nos livros didáticos impedem certas formas de conhecimento, como a contra-memória e a crítica da ideologia, que o 'alfabetismo da diáspora', em contraposição, permite e que a liberdade humana exige (KING, 1996, p. 76).

Portanto, a decifração do conhecimento, ao lado do exercício de alfabetismo da diáspora, são os interesses deste texto, cujo objetivo é duplo: refletir sobre o currículo predominante na educação brasileira e propor práticas pedagógicas que protagonizem a Educação das Relações ÉtnicoRaciais. Ainda mais se considerarmos que a educação demanda, conforme argumenta Nilma Lino Gomes (2012, p. 102), "a necessidade de diálogo entre escola, currículo e realidade social, a necessidade de formar professores e professoras reflexivos e sobre as culturas negadas e silenciadas nos currículos", para projetar as vozes de tais culturas, o currículo, então, precisa ser repensado.

Em certa medida a Lei 10.639 de 2003, responsável por modificar O artigo 26A da Lei de Diretrizes e Bases da Educação Nacional (LDB) e tornando obrigatório o ensino da história e cultura africana e afro-brasileira, repercutiu no currículo. Essa modificação provocou uma maior atenção à legislação educacional por produzir "uma mudança cultural e política no campo curricular e epistemológico" (GOMES, 2012, p. 105).

Entretanto, tal mudança ainda em curso - e reconhecemos que a passos lentos - envolve uma ampliação da noção de cultura e de diferença. Especialmente a noção de diferença é, para o currículo, um aspecto ainda muito fragilmente operado, a ponto de tomarmos questões propostas por Achille Mbembe $(2016$, p. 1) como um primeiro ponto de nossa investigação: 
"Por que é que achamos que a diferença é um problema? Por que ela não é simplesmente um fato da realidade?".

\section{DESOCULTAR O CURRÍCULO: a noção de diferença}

As indagações de Mbembe (2016) mobilizam em nós outras: se a diferença constitui a realidade, por qual motivo ela não é encarada como fato? Por que é recorrente o distanciamento diante do dessemelhante? Em resposta, o autor nos lembra de que a diferença só aparece como problema quando se acredita que o normal é aquilo que é igual. Essa compreensão impele para as ações modernas de contato violento entre povos, bem como para o prevalecimento do colonialismo e do racismo como maneira de hierarquizar os povos:

No momento em que começamos a fazer classificações, institucionalizar hierarquias em nome da diferença, como se as diferenças fossem naturais e não construídas, acreditando que são imutáveis e, portanto legítimas, aí sim estamos em apuros (MBEMBE, 2016, p. 1).

Tais classificações são formuladas por meio da mensuração do estrangeiro a partir de um "eu" que questiona o fato de o "outro" não ser física e culturalmente igual a mim. Essas inquietações, para Mbembe (2016, p. 2), mostram que a diferença passou a ser "uma questão de separação, de construir muros, de militarizar fronteiras, imunizar corpos contra ameaças externas, reais e inventadas". E o currículo, o conhecimento, a escola e tudo neles imbricados sofrem diretamente o impacto desse modo de interpretar as diferenças.

Tomaz Tadeu da Silva (2017) comenta como a "virada culturalista" no campo da teoria do currículo estreitou cada vez mais as fronteiras entre o conhecimento acadêmico, escolar e o conhecimento cotidiano, de massa. E esse estreitamento faz com que "todo conhecimento, na medida em que se constitui num sistema de significação, é cultural" e, por efeito, "todo conhecimento está estreitamente vinculado com relações de poder" (SILVA, 2017, p. 139). 
Tais transformações no âmbito escolar compõem aquilo que é denominado de "currículo oculto". Para a perspectiva crítica de currículo, é oculto porque, sem fazer parte do currículo oficial, contribui, fundamentalmente, para a formação de "atitudes, comportamentos, valores e orientações que permitem que crianças e jovens se ajustem de forma mais conveniente às estruturas e às pautas de funcionamento, consideradas injustas e antidemocráticas" (SILVA, 2017, p. 78).

As narrativas do currículo, tais como estão escritas em sua maioria, favorecem a difusão do currículo oculto, pois contam histórias coloniais e fixam noções particulares de raça, classe, gênero, sexualidade e idade. Essas noções consolidadas pelo currículo são reforçadas pelas relações de poder, pela pobreza, pela exploração capitalista, pelo racismo e pelo sistema patriarcal, e forjam subjetividades e práticas coloniais e colonizadoras. Por isso, é preciso descolonizar o currículo:

A descolonização do currículo implica conflito, confronto, negociações e produz algo novo. Ela se insere em outros processos de descolonização maiores e mais profundos, ou seja, do poder e do saber. Estamos diante de confrontos entre distintas experiências históricas, econômicas e visões de mundo. Nesse processo, a superação da perspectiva eurocêntrica de conhecimento e do mundo torna-se um desafio para a escola, os educadores e as educadoras, o currículo e a formação docente. Compreender a naturalização das diferenças culturais entre grupos humanos por meio de sua codificação com a ideia de raça; entender a distorcida relocalização temporal das diferenças, de modo que tudo aquilo que é não-europeu é percebido como passado e compreender a ressignificação e politização do conceito de raça social no contexto brasileiro são operações intelectuais necessárias a um processo de ruptura epistemológica e cultural na educação brasileira (GOMES, 2012, p. 108)

Se observarmos brevemente os estudos realizados sobre o impacto da mudança na LDB provocada pela Lei 10.639/2003, já constataremos que os resultados assemelham-se no tocante às dificuldades/resistências/obstruções ao estabelecimento de um currículo descolonizado. Um recente levantamento de Mauro Cezar Coelho e Wilma de Nazaré Baía Coelho (2018) sobre cursos de licenciatura em História em instituições de ensino superior no Brasil identificou características marcantes. Com o objetivo de 
"analisar o espaço destinado à formação para as relações étnico-raciais e para o trato com a diferença" (COELHO; COELHO, 2018, p. 1), o autor e a autora investigaram dez projetos políticos pedagógicos de universidades federais, sendo dois de cada região ${ }^{4}$. Entre os resultados, destaca-se um que mais bem caracteriza a "face" de grande parte dos cursos de História no Brasil:

A Europa é espaço absoluto de atenção em disciplinas voltadas para a compreensão de processos que nela ocorreram, como é o caso de História Antiga, História Medieval, História Moderna e História Contemporânea. Em seguida, a mesma Europa aparece como epicentro dos eventos que regulam processos em outras partes do globo - situação frequente em disciplinas voltadas para o trato com os processos de colonização da América (seja tratando do continente, nas disciplinas regularmente denominadas de História da América I, seja nas disciplinas voltadas para a abordagem da História do Brasil, identificadas, via de regra pelo numeral romano I), mas presentes também em disciplinas relativas à História da África, História Indígena, História da América ou do Brasil independentes e nas disciplinas de natureza teórico-metodológica. Nestas últimas, é meramente incidental a referência às perspectivas decoloniais que buscam estabelecer uma crítica à orientação eurocêntrica (COELHO; COELHO, 2018, p. 15).

Se compararmos esse quadro com a constatação de King (1996) acerca dos livros didáticos de História por ela analisados na década de 1990 nos Estados Unidos, podemos afirmar que de maneira análoga estão vários dos cursos de formação de docentes em História no Brasil: produzindo uma "deseducação da comunidade negra" (KING, 1996, p 76). É uma deseducação, pois omite ou distorce "certos signos culturais" que, se fossem apresentados "da forma verdadeira e com integridade, poderia[m] abrir os olhos de uma quantidade maior 'de novos imigrantes' [no caso particular da autora: os Estados Unidos] e brancos nativos [...] relativamente aos mitos americanos" (KING, 1996, p. 83).

\footnotetext{
${ }^{4}$ Segundo Coelho e Coelho (2018, p. 6): "As instituições foram escolhidas em função de um critério fortuito - ter o projeto político pedagógico disponibilizado na rede mundial de computadores. Selecionamos, então, os projetos dos cursos de formação ofertado pelas universidades federais do Amapá (UNIFAP), Ceará (UFC), Goiás (UFG), Mato Grosso (UFMT), Minas Gerais (UFMG), Paraná (UFPR), Piauí (UFPI), Rio de Janeiro (UFRJ), Roraima (UFRR) e Santa Catarina (UFSC). Esse conjunto mostrou-se diversificado e permitiu a formação de um quadro que consideramos representativo da oferta de cursos de licenciatura em História no país - especialmente nas universidades federais".
}

Revista Exitus, Santarém/PA, Vol. 9, № 4, p. 147 - 175, Out/Dez 2019. 
Se não refletido e assumido pelo currículo que perpassa a formação docente e a educação básica no Brasil, esse processo de deseducação tende a se consolidar cada vez mais, a ponto de produzir com maior ênfase uma "perspectiva eurocêntrica e que assume a formação docente como uma instrumentalização do saber de referência para fins didáticos" (COELHO; COELHO, 2018, p. 25), desconsiderando os princípios constitucionais da educação brasileira de formação para a cidadania ou, em outras palavras, de "formar para uma crítica à memória, formar para a conformação de uma sociedade que combate preconceitos" (COELHO; COELHO, 2018, p. 15).

É no intento de então avaliar possibilidades de um "alfabetismo da diáspora" como modo de enfrentamento da deseducação, que na seção seguinte discutiremos propostas de formação de professores/as a partir da disciplina de Educação das Relações Étnico-Raciais 5 .

\section{UMA DISCIPLINA QUE SE PROPÕE SEM GRADES}

Como lidar pedagogicamente com a resistência na sala de aula no trabalho com história e cultura afro-brasileira e africana? E mais: como desenvolver uma formação docente que não produza mais deseducação? Os efeitos da deseducação acabam por incidir, também, nos livros didáticos. Van Dijk (2008, p. 149) aponta que "muitos livros didáticos contemporâneos em vários países ocidentais continuam a ser, basicamente, eurocêntricos [...]. Eles continuam a repetir os estereótipos sobre minorias e sobre outros povos não europeus". Assim, o trabalho de formação docente passa a ser duplo, pois precisa romper com uma formação tradicional e também provocar o olhar dos/as docentes para os materiais didáticos que lidam diariamente. Por isso, as possíveis respostas para ambas as perguntas perpassam, no nosso entendimento, por dois elementos elencados por King

\footnotetext{
5 Esta nomenclatura será registrada com iniciais maiúsculas sempre que se referir à disciplina. Quando se tratar de um conceito oriundo do Parecer CNE/CP 03/2004, será registrado com fontes em minúsculo.
} 
(1996) como fundamentais: a decifração do conhecimento e o alfabetismo da diáspora.

É sobre tais princípios que analisaremos o componente curricular da disciplina de Educação das Relações Étnico-Raciais (Erer) para os cursos de licenciatura. Criada em 2017 na Universidade Federal do Espírito Santo (Ufes), tal disciplina, com carga horária de 60 horas, está alocada no Centro de Educação e é ministrada por três docentes com formação e experiência em áreas da Educação das Relações Étnico-Raciais. A proposta é de analisar o conteúdo programático (referencial teórico e fundamentos filosóficos) de uma dessas docentes.

A disciplina de Erer, que foi inicialmente oferecida em caráter optativo para os cursos de licenciatura da Ufes, passou a ser obrigatória para todos os cursos com a aprovação de seus Projetos Pedagógicos de Curso (PPC). Assim, a partir de 2018 para alguns cursos e de 2019 para outros, a Erer passa a compor obrigatoriamente o rol de disciplinas mínimas para a conclusão de uma licenciatura. Isso coaduna com os princípios no Parecer $n^{\circ} 3 / 2004$, do Conselho Nacional de Educação, que instituiu as "Diretrizes Curriculares Nacionais para a Educação das Relações Étnico-Raciais e para o Ensino de História e Cultura Afro-Brasileira e Africana" (BRASIL, 2004). Tal documento estabelece tanto a necessidade de inclusão "nos conteúdos de disciplinas e em atividades curriculares dos cursos que ministra, de Educação das Relações Étnico-Raciais, de conhecimentos de matriz africana e/ou que dizem respeito à população negra", quanto de discussão das relações raciais "como parte integrante da matriz curricular" dos cursos de licenciatura, "como de processos de formação continuada de professores, inclusive de docentes no Ensino Superior" (BRASIL, 2004).

Fica evidente, portanto, que um dos princípios da disciplina de Erer é de atender aos preceitos das referidas Diretrizes, incluindo o de reeducação do olhar sobre as relações étnico-raciais. Por isso ela se fundamenta em quatro eixos: aspectos sócio-históricos; aspectos culturais e estéticos; África e conhecimentos da diáspora; propostas e práticas pedagógicas. Antes de suas respectivas apresentações, cabe destacar que imiscuídos neles estão 
princípios aqui nomeados de "Rede de afetos/cuidados". São princípios pensados a partir da compreensão de que muitos dos temas debatidos na disciplina revelam-se, para o grupo de estudantes, densos e de difícil lida do ponto de vista subjetivo, pois refazem, por outra via, a história do Brasil e também suas próprias trajetórias. E é um processo pertinente, já que para "reeducar as relações étnico-raciais, no Brasil, é necessário fazer emergir as dores e medos que têm sido gerados" (BRASIL, 2004). Por isso a necessidade de redes de afeto/cuidado: para acolher, incluir, respeitar, valorizar e reconhecer as diversas trajetórias dos membros da turma que se constituem, a partir do seu ingresso na disciplina, corresponsáveis pelos demais que seguem rumo à tarefa de reeducação do olhar.

Os princípios envolvem, então, modos de ver, de sentir, de ouvir e de falar e têm como eixo três outros aspectos: outridade - a consideração da existência do outro e dos diferentes percursos sócio-históricos do outro -; privilégio - a compreensão de que não é pelo fato de o privilégio ser imperceptível, muitas das vezes, que ele não exista e não exponha a desigualdade de outros ${ }^{6}$-; consciência - a noção de que só é possível uma reeducação do olhar a partir da tomada de consciência sobre si no mundo e sobre os outros.

E no tocante aos eixos do conteúdo programático, o primeiro "Aspectos sócio-históricos" - discute conceitos de raça, etnia, discriminação, preconceito, mito da democracia racial e racismo à brasileira; também são explorados elementos sobre a condição histórica das populações negra e branca no Brasil, refletindo tanto sobre o ponto de partida quanto sobre os prejuízos ou vantagens cumulativos para cada um dos grupos no Brasil a partir do critério racial. Esse intento representa a "decifração do conhecimento" que King (1996) propõe a partir dos Estudos Negros: ao desnudar momentos históricos ou a oferecer outros olhares, desenvolve-se um "ponto de vista alternativo, a partir do qual se possa resgatar tanto a

\footnotetext{
6 Como nos lembra o Parecer CNE 03/2004: "Se não é fácil ser descendente de seres humanos escravizados e forçados à condição de objetos utilitários ou a semoventes, também é difícil descobrir-se descendente dos escravizadores, temer, embora veladamente, revanche dos que, por cinco séculos, têm sido desprezados e massacrados".
} 
história quanto a memória da distorção ideológica causada pela política epistemológica" (KING, 1996, p. 78).

Nesse sentido, autores e autoras de diversas áreas são convocados por meio de textos como os seguintes: "Uma abordagem conceitual das noções de raça, racismo, identidade e etnia", de Kabengele Munanga (2000); "A formação do mercado de trabalho e a questão racial no Brasil", de Mário Theodoro (2008); "Preconceito racial de marca e preconceito racial de origem", de Oracy Nogueira 2006 [1955]; "Branquitude e branqueamento no Brasil", de Maria Aparecida Silva Bento (2002).

O segundo eixo, "Aspectos culturais e estéticos", provoca a reflexão sobre a existência física e simbólica da população negra no Brasil, tomando elementos como discriminação, resistência, beleza, cabelo, corpo, gênero e sexualidade como motes para 0 debate. São também textos intergeracionais, pois discutem a condição da criança negra - sobretudo no ambiente escolar - e a vida adulta de mulheres e homens negros numa sociedade racializada e esteticamente valorativa do corpo branco. Entre o grupo de autoras desse eixo destacam-se: Eliane Cavalleiro (2006), Nilma Lino Gomes (2005) e Megg Rayara Gomes de Oliveira (2017).

No eixo "África e conhecimentos da diáspora" são propostas discussões sobre outras versões da história, com vistas a desenvolver o "alfabetismo da diáspora", perspectiva que visa possibilitar que "o povo negro re-possua 'nossa história'" (KING, 1996, p. 82), não o tomando com um construto "para privilegiar ou impedir formas específicas de diferença" (KING, 1996, p. 82), mas para constatar o óbvio: "As pessoas precisam aprender o mundo tanto em sua particularidade quanto em sua 'totalidade social'” (KING, 1996, p. 82). É o que também estabelecem as Diretrizes, documento balizador dessa disciplina, ao afirmar a necessidade de:

[...] divulgação e produção de conhecimentos, a formação de atitudes, posturas e valores que eduquem cidadãos orgulhosos de seu pertencimento étnico-racial - descendentes de africanos, povos indígenas, descendentes de europeus, de asiáticos - para interagirem na construção de uma nação democrática, em que 
todos, igualmente, tenham seus direitos garantidos e sua identidade valorizada (BRASIL, 2004).

Nesse eixo destacam-se nomes como Oyèrónké Oyěwùmí (2004), Elisa Larkin Nascimento (2008) e Henrique Cunha Júnior (2005), que oferecem referenciais históricos, culturais e estéticos muito mais alargados do que a formação básica forneceu acerca da África e dos africanos da diáspora. A condição da mulher é reapresentada, provocando as noções limitadas do Ocidente sobre as culturas africanas; da mesma maneira as noções de escravização e servidão são revistas, oferecendo olhares mais ampliados sobre uma dicotomia conceitual presente na disputa da narrativa do currículo entre "Holocausto africano" e "imigração forçada". Especialmente esse debate chama a atenção sobre os discursos embutidos em cada uma das perspectivas $e$ as estratégias do currículo hegemônico de "autoapresentação positiva e outra apresentação negativa" (VAN DIJK, 2008, p. 252), que inclui as seguintes características:

- Macroato de fala indicando Nossos 'bons' atos e os 'maus' atos dos Outros; por exemplo, acusação, defesa;

- Macroestruturas semânticas: seleção de tópicos:

- (des)enfatizar pontos negativos ou positivos sobre Nós/Eles; [...] (VAN DIJK, 2008, p. 252-253).

E ainda que seja uma disciplina de carga horária insuficiente para o aprofundamento que tais debates suscitam, ela possibilita, com esses três primeiros eixos, um avanço significativo para o grupo de estudantes evolvidos no modo de pensar suas áreas de formação. Ao concordarmos com a assertiva de Coelho e Coelho $(2018$, p. 24) de que "os entraves experimentados pelos sistemas educacionais no processo de implementação [da Erer] são, em larga medida, decorrentes da formação inicial ofertada aos futuros professores", desenvolver já na formação inicial uma capacidade de decifrar os conhecimentos que permeiam os currículos, sejam eles da sua própria formação ou da sua atuação profissional, é um passo primordial. 
Paralelamente às discussões a partir dos textos, o conjunto de recursos audiovisuais contribui para a ampliação dos debates, com destaque para o documentário "A negação do Brasil" (2000), de Joel Zito Araújo, o clipe musical "A coisa tá preta" (2017), de Rincon Sapiência, e o filme ficcional "Pantera Negra" (2018), de Ryan Coogler.

Munidos de diversas frentes conceituais e de uma gama de referenciais teóricos e práticos, o último eixo, "Propostas e práticas pedagógicas", aciona o protagonismo do corpo discente na disciplina, pois, tomando como base as Diretrizes aqui já mencionadas, são desenvolvidas propostas pedagógicas de intervenção na educação básica a partir de suas áreas de formação. Como recorrentemente a disciplina de Erer não é procurada apenas por estudantes de um único curso, mas por vários, a produção de tais propostas - que algumas delas se tornam práticas pedagógicas - torna-se mais enriquecida e inter/transdisciplinar7. Nesse momento também é possível avaliar em que medida os textos, os debates, as tensões e as redes de afeto/cuidado foram captadas pelo grupo. As diversas vozes produzem, coletivamente, reflexões que acionam uma (auto)avaliação, tanto de si próprios quanto da disciplina e da atuação da docente, incidindo diretamente nas experiências futuras de todos os envolvidos, compreendendo que "a educação das relações étnico-raciais impõe aprendizagens entre brancos e negros, trocas de conhecimentos, quebra de desconfianças, projeto conjunto para construção de uma sociedade justa, igual, equânime" (BRASIL, 2004).

É com a compreensão da importância da educação das relações étnico-raciais, que a seção seguinte avaliará com mais profundidade como tais mudanças podem incidir na prática docente em uma das disciplinas do currículo da educação básica: a Filosofia.

\footnotetext{
7 Não discutiremos o mérito dos conceitos de interdisciplinar ou transdisciplinar. Para mais profundidade no tema, ver Roberto Sidnei Macedo (2013).
} 


\section{OUTRAS NARRATIVAS NO CURRÍCULO DE FILOSOFIA}

A escolha pela disciplina de Filosofia se justifica pela usual articulação entre uma suposta origem e desenvolvimento (que defende que ambos seriam na Europa) e os conteúdos curriculares que o/a docente precisa ministrar em sala de aula. Essa articulação condicionou a imagem sobre quem produz filosofia: o homem branco como um sujeito epistêmico neutro. Dessa maneira, autores e autoras não correspondentes a essa imagem são questionados se produzem filosofia ou apenas seriam compiladores/as de saberes.

Essa situação, não gratuitamente para Charles Mills (1997), expõe a particularidade da filosofia acadêmica: "tanto demograficamente e conceitualmente, é uma das 'mais brancas' (whitetest) das humanidades" (MILLS, 1997, p. 2). Portanto, essa pode ser uma das disciplinas mais beneficiadas com a efetividade da Educação das Relações Étnico-Raciais, por ampliar as narrativas curriculares de filosofia e suas epistemologias.

De modo geral, a construção do currículo vincula-se, inicialmente, com a escolha da metodologia que direciona para a categorização dos conteúdos. As metodologias habituais para o ensino de filosofia no Brasil são a "histórica", a "temática" e a "problemática". A "histórica" tem uma relação com a maneira hegeliana de entender a própria filosofia, já que para Hegel a filosofia é uma expressão do espírito que se desenvolve historicamente e os conceitos possuem uma referência com o tempo que o produziu. A "temática" aproxima-se da ideia kantiana de que a filosofia não é um artifício que possa ser aprendido, mas que a aprendizagem se deve ao ato de filosofar, orientado pela razão. A "problemática" parte da compreensão deleuziana de que a filosofia é uma criação de conceitos e se envolve através dos problemas que o campo imanente (situado na vida) do pensamento se depara.

No âmbito brasileiro, alguns documentos oficiais privilegiam uma metodologia em relação à outra. Nos Parâmetros Curriculares Nacionais + (PCN+) de Ciências humanas e suas tecnologias (2006), por exemplo, no que se refere à filosofia predomina a abordagem "temática". Já as Orientações 
Curriculares para o Ensino Médio (2006) privilegiam a "histórica", tendo como base a linha Antiga (Grécia), Medieval, Moderna e Contemporânea. As metodologias que compõem cada um dos documentos revela o entendimento institucional da própria atividade filosófica. No caso das Orientações, por exemplo, o ensino enfoca os pensamentos filosóficos canônicos, de modo que a leitura do "texto pelo texto" exalta os princípios fundantes de tais pensamentos. Já o PCN+ tende a aproximar a filosofia do cotidiano através de diversos eixos, como: relações de poder e democracia, a construção do sujeito moral e o que é filosofia. Por consequência, tanto em um, como no outro documento, há um entendimento de quais conteúdos e filósofos são importantes para o desenvolvimento, no discente, da "capacidade para responder, lançando mão dos conhecimentos adquiridos, as questões advindas das mais variadas situações" (BRASIL, 2006, p. 29).

Embora não conste em documento oficial, a metodologia "problemática", proposta por Silvio Gallo (2006), destaca-se no campo do ensino de filosofia, pois está presente em muitos livros didáticos organizados pelo autor. Centralizado na aprendizagem da filosofia como experiência do pensar, o autor parte de quatro etapas (sensibilização, problematização, investigação e conceituação) para propor um ensino de filosofia que trate dos problemas cotidianos de forma prática e criativa.

Inspirada nessa perspectiva, o que se propõe nessa seção é uma reflexão metodológica com destaque para as emergências sociais de raça, de etnia, de gênero, de sexualidade e de idade acerca de quem filosofa. $O$ ponto principal de tal proposta é, portanto, a correspondência entre o pensamento e sua localidade.

Desse modo, o quem certifica o locus da enunciação do discurso filosófico produzido por um corpo permeado de relações de poder, invalidando a crença da existência de um "sujeito epistêmico neutro". É nesse sentido que Maldonado-Torres (2008) denuncia uma habitual ausência de reflexões geopolíticas a respeito de como a espacialidade impõe uma legalidade ao conhecimento, pois não há uma avaliação da "falta de 
reflexão crítica quanto ao empenhamento da filosofia e dos filósofos ocidentais com a Europa enquanto local epistêmico privilegiado" (MALDONADO-TORRES, 2008, p. 73). A espacialização da filosofia refere-se, assim, a uma análise, ou até mesmo a uma descrição acerca da existência de conceitos pré-concebidos filosoficamente em certos âmbitos; já a territorialização pressupõe a existência de conceitos filosóficos e propõe que interajam entre si, mesmo que ocorram modificações estruturais.

A tendência à espacialidade da filosofia decorre da própria modernidade europeia que a tratou como uma ideia que não se preocupa em "explicar o seu lugar, mas em delinear seu espaço" (JANZ, 2008, p. 101), ou seja, o seu alcance para adentrar nos locais "ausentes" de filosofia: "novas terras não estão mais fora dos limites, pertencendo a Deus e a monstros, mas são acessíveis a qualquer um que encontre o caminho até lá e hasteie uma bandeira" (JANZ, 2008, p. 104). Por consequência, isso provoca, para a compreensão da filosofia, um "novo locus da ideia de um observador ou observadora distanciado/a que só é capaz de examinar as intrincadas relações entre conhecimento e ideias de espaço porque, no fundo, se encontra para lá dessas relações" (MALDONADO-TORRES, 2008, p. 73).

Já com o foco no território, a filosofia atua não somente nas vias de produção de conhecimento, mas também na caracterização do território de quem produz. Assim as emergências oriundas de um espaço não são as mesmas em relação a outros territórios, como pode ser ilustrado, por exemplo, pela interrogação: "existe uma filosofia africana?". Ela carrega um grau de essencialismo por justamente buscar uma homogeneidade cultural dessa filosofia e, também, por cercear os limites espaciais do que seria a filosofia africana. Por outro lado quando se interroga: "o que significa fazer filosofia neste lugar (África)?" (JANZ, 2008, p. 112), não há uma redução dessa filosofia ao problema da posse e sim a constituição da experiência de produzir filosofia nesse local: 
[a questão] [...] assume que já há um significado contido em um mundo-vida, em vez de supor que ele tem de ser criado ou justificado. Isso não significa que a filosofia africana deva ignorar a tradição, razão, linguagem, cultura e praticidade como conceitoschave - bem o contrário. Mas cada um desses conceitos comportase como todos os outros conceitos, como marcadores de um território viajado e de uma paisagem habitada. [...]. Esse território não pode ser determinado essencialmente - o pássaro vai aonde quer, e não deixa de ser o que é se seu território muda de um ano para o outro. Ele é nômade (JANZ, 2008, p. 107).

Esse nomadismo dificulta a espacialização conceitual da filosofia africana já que o recorte epistemológico baseado em conceitos "universalistas" como tradição, razão, linguagem, cultura e ação prática apenas delimitam um marcador espacial e não o território, o lugar, dessa filosofia: "não há nada inerente em qualquer conceito que faça dele um conceito filosófico ou africano [...]. Focalizar neles apenas é perder de vista sua territorialidade" (JANZ, 2008, p. 112).

Ratificando King (1996) sobre a necessidade de "decifração do conhecimento" e de exercer o "alfabetismo da diáspora" como resposta à omissão e à distorção da influência histórica africana no mundo, a proposta de pensar a filosofia a partir do território aciona o princípio de uma pluriversalidade curricular, de modo a justificar que "a filosofia é a multiplicidade das filosofias particulares vividas num dado ponto do tempo" (RAMOSE, 2011, p. 12) e legitimar as vozes silenciadas e invisibilizadas no currículo universal. Com essa exposição das características do território metodológico, então podemos relatar experiências curriculares que "denigrem" a filosofia (NOGUERA, 2011) em prol de um "trânsito étnico" (MILLS, 1997) em seus conteúdos.

\section{EXPERIÊNCIA DE DESCOLONIZAÇÃO CURRICULAR}

As experiências práticas aqui apresentadas são oriundas de localidades diferentes: as duas primeiras do Instituto Federal do Espírito Santo - Campus de Linhares (Ifes), no ano de 2018, e a terceira de uma escola pública estadual de Colombo (região metropolitana de Curitiba - PR), no ano de 2016. Com essas diferenças geográficas, a experiência de uma 
descolonização curricular (ou também uma decifração do conhecimento) aconteceu da seguinte forma: i) uma análise dos documentos estaduais das Secretarias de Educação dos Estados do Paraná e do Espírito Santo, atentando para os direcionamentos dos conteúdos filosóficos; ii) uma leitura das Orientações Curriculares do Ensino Médio acerca dos conteúdos obrigatórios para o ensino de filosofia; iii) avaliação de quais conteúdos possibilitariam a inserção de perspectivas epistêmicas não-ocidentais; iv) desenvolvimento, em sala de aula, das perspectivas e estímulo às interferências dos estudantes sobre os conteúdos ministrados.

No tocante à primeira etapa, foram observadas algumas diferenças e aproximações entre os dois documentos estaduais. No Paraná há as Diretrizes Curriculares para a disciplina de filosofia, cujo objetivo é fundamentar teoricamente os aspectos metodológicos para implantação da disciplina na sala de aula. Nesse documento a metodologia escolhida foi a "temática", a qual, a partir dos eixos "mito e filosofia, teoria do conhecimento, ética e filosofia política, estética e filosofia da ciência" (PARANÁ, 2008, p. 42), foi elencada uma série de temas com fundamentos europeus, com breves referências a outras localidades. Por exemplo, sobre o continente africano reservou-se um parágrafo anunciando a dificuldade em tratar de filosofia africana:

No entanto, se a filosofia africana traz como vantagem a ideia de que o ser é dinâmico, dotado de força - concepção essa que aparece também em algumas filosofias ocidentais - é preciso considerar que a sua fundamentação exclusiva na linguagem oral, ainda que pareça interessante, acaba por apresentar-se como uma fragilidade, evidenciada pela dificuldade com o idioma e também pela carência de bibliografia. Por essa razão, esse conteúdo não está relacionado entre os que compõem os conteúdos estruturantes de Filosofia, podendo, todavia, ser tratado na qualidade de conteúdo básico (PARANÁ, 2008, p. 40).

No Espírito Santo há um Currículo Base (2009) para a educação básica, cuja preocupação relaciona-se com 0 modo como as disciplinas contribuem, entre as quais a filosofia, para a formação humana. Tal documento aproxima-se da abordagem "problemática" que, definida 
como "cultura filosófica", trata das competências e dos respectivos conteúdos filosóficos "mais do que 'temas', uma série de questões conceituais para se estabelecer uma discussão e formação filosófica" (ESPIRITO SANTO, 2009, p. 62, grifos do autor). Contudo, mesmo sugerindo os eixos - sentir, existir, relacionar-se e fazer; pensar e conhecer; agir e transformar -, ainda assim, há uma construção de referenciais teóricos europeus, à exceção de Santo Agostinho, nascido em Tagaste no Norte da África. A grande maioria dos nomes citados é de homens e sem qualquer menção a filosofias não ocidentais. Com isso vale utilizar a retórica para questionar: se o objetivo da disciplina de filosofia é a formação humana, então para se tornar humano é preciso assumir e viver o pensamento e os valores europeus? Por esse modo, em âmbito estadual, especialmente do Espírito Santo, não há qualquer suporte oficial no currículo para o trabalho pedagógico com filosofias não ocidentais, ficando a cargo e interesse meramente do docente, a depender do seu conhecimento e vontade de abordar filosofias africana ou latino-americana, por exemplo.

Em âmbito federal, nas Orientações Curriculares são categorizados trinta tópicos de uma história da filosofia, ao privilegiar a metodologia histórica:

1) Filosofia e conhecimento; Filosofia e ciência; definição de Filosofia; 2) validade e verdade; proposição e argumento; 3) falácias não formais; reconhecimento de argumentos; conteúdo e forma; 4) quadro de oposições entre proposições categóricas; inferências imediatas em contexto categórico; conteúdo existencial e proposições categóricas; 5) tabelas de verdade; cálculo proposicional; 6) filosofia pré-socrática; uno e múltiplo; movimento e realidade; 7) teoria das ideias em Platão; conhecimento e opinião; aparência e realidade; 8) a política antiga; a República de Platão; a Política de Aristóteles; 9) a ética antiga; Platão, Aristóteles e filósofos helenistas; 10) conceitos centrais da metafísica aristotélica; a teoria da ciência aristotélica; 11) verdade, justificação e ceticismo; 12) o problema dos universais; os transcendentais; 13) tempo e eternidade; conhecimento humano e conhecimento divino; 14) teoria do conhecimento e do juízo em Tomás de Aquino; 15) a teoria das virtudes no período medieval; 16) provas da existência de Deus; argumentos ontológico, cosmológico, teleológico; 17) teoria do conhecimento nos modernos; verdade e evidência; ideias; causalidade; indução; método; 18) vontade divina e liberdade humana; 19) teorias do sujeito na filosofia moderna; 20) o contratualismo; 21) razão e entendimento; razão e sensibilidade;

Revista Exitus, Santarém/PA, Vol. 9, № 4, p. 147 - 175, Out/Dez 2019. 
intuição e conceito; 22) éticas do dever; fundamentações da moral; autonomia do sujeito; 23) idealismo alemão; filosofias da história; 24) razão e vontade; o belo e o sublime na Filosofia alemã; 25) crítica à metafísica na contemporaneidade; Nietzsche; Wittgenstein; Heidegger; 26) fenomenologia; existencialismo; 27) Filosofia analítica; Frege, Russell e Wittgenstein; o Círculo de Viena; 28) marxismo e Escola de Frankfurt; 29) epistemologias contemporâneas; Filosofia da ciência; o problema da demarcação entre ciência e metafísica; 30) Filosofia francesa contemporânea; Foucault; Deleuze (BRASIL, 2006, p. 34-35).

Como se pode observar entre tais tópicos, a temática étnico-racial é mencionada apenas duas vezes e somente para referenciar a filosofia alemã e francesa e outras duas vezes para expressar locais produtores de filosofia: Frankfurt e Viena. Mas ainda que os documentos aqui arrolados (em âmbito estadual ou federal) fundamentem-se em princípios eurocêntricos, a organização curricular de uma disciplina tende a atender o máximo possível dos eixos. Nos exemplos de práticas pedagógicas que compõem esta seção, por exemplo, partimos de três categorias das Orientações, mas intencionando desenvolver o trabalho em sala com perspectivas epistêmicas não ocidentais, na busca de uma descolonização curricular: "6) filosofia pré-socrática; uno e múltiplo; movimento e realidade; 22) éticas do dever; fundamentações da moral; autonomia do sujeito; 30) Filosofia francesa contemporânea; Foucault; Deleuze" (BRASIL, 2003, p. 37).

No IFES, inicialmente em uma turma de primeiro ano do ensino médio, abordamos a categoria 6. Como ela destaca a filosofia pré-socrática e a oposição teórica entre Parmênides (Uno) e Heráclito (Múltiplo), então apresentamos a filosofia no Egito antigo, seja explicando como o nome Kemet corresponde a esse território do norte da África, seja informando que por muito tempo Kemet foi um local de trocas comerciais, culturais e filosóficas; ou, ainda demonstrando como Rekhet, uma prática exercida pelos escribas, consistiu na arte de aperfeiçoar o conhecimento que posteriormente foi traduzido por filosofia. E justamente por causa da presença de Rekhet que a distinção do Uno e do Múltiplo já se encontraria antes da filosofia grega. 
Essa distinção relaciona-se com a concepção de "Existente", que pode ser interpretado como aquilo que decorre da própria força (ba), pois o "Existente" engendra-se, por si mesmo e para si mesmo, "antes da criação, antes das coisas desejadas e almejadas pelo Uno" (OBENGA, 1990, p. 58). E, por causa desse desejo, a derivação do múltiplo ocorre por meio da vontade e não por um conhecimento racional, pois vontade e razão são unificadas pelo amor, um ímpeto produzido através de um importante conceito para a filosofia kemética: o coração (Ib).

Dialética do Uno e do Múltiplo: 'os modos de existência que derivam do Existente foram múltiplos' (âsha khperou nou Khepri). O Existente gera realmente outros modos de existência por amor (merouty: irry.i mrwty nbt $m+3 \mathrm{pn}$ ) e por sua própria vontade (iri), sendo alma (wci.kwi) por sua própria potência. O ser é absoluto; ele é também amor e vontade (OBENGA, 1990, p. 59, grifos nossos).

E na continuidade da aula, a existência da filosofia atrelada à presença de humanos que interrogam sobre as situações do mundo ficava cada vez mais explícita. Dessa maneira, não houve uma ruptura ou uma descontinuidade com a filosofia grega, mas um intercâmbio com a filosofia kemética. Uma das principais intervenções, feitas por um estudante em sala de aula, após a leitura do livro didático que afirmava uma origem grega da filosofia foi: "Professor, o pensamento filosófico não é uma atividade humana? Então como pode ter origem em um país?" (Nota de campo, maio/2018). A partir de tal indagação houve uma discussão sobre como o eurocentrismo legitima a produção de conhecimentos. Para tanto, foram acionadas imagens e excertos textuais de Cheikh Anta Diop, Théophile Obenga e Amenemope.

Ainda na mesma instituição, a categoria "22 éticas do dever; fundamentações da moral; autonomia do sujeito", discutida em uma turma do $2^{\circ}$ ano do ensino médio, fomentou o debate sobre a transformação das concepções éticas antropocêntricas e da problematização da ideia de indivíduo. Para isso, destacamos da ética antropocêntrica (inicialmente com Aristóteles) à mediania, como forma de o ser humano obter a felicidade que é a finalidade de todas as ações humanas. Em seguida foi apresentado 
o dever como aquilo que não pode se relacionar a qualquer interesse da sensibilidade (a ideia de moral em Immanuel Kant). Por fim, questionamos, a partir de Friederich Nieztsche, como a noção de bem e mal são interpretações morais dos fenômenos. Após essa tríade, tomamos duas perspectivas para pensar uma ética além do antropocentrismo: a ética animal, desenvolvida por Peter Singer (2018) e a ética comunitária de Ubuntu, na interpretação de Mogobe Ramose (2011).

Se para Singer o julgamento do valor ético corresponde ao quanto de sofrimento deriva das nossas ações, então aquilo que afeta aos demais animais, apenas para o bel prazer humano, precisa ser repensado eticamente. E com Ubuntu, palavra de origem bantu dos idiomas Ndebele, Swati, Xhosa e Zulu, os efeitos das nossas ações não correspondem somente aos viventes humanos e animais, mas também aos ancestrais e aos vindouros, com a pretensão de estabelecer harmonia:

Os africanos estão em uma busca da harmonia em todas as esferas da vida. A conclusão que africanos estão persistentemente em busca de harmonia em todas as esferas da vida é um consenso mirado para estabelecer harmonia (RAMOSE, 2003, p. 276).

Com isso, três pontos da exposição na aula derivaram a partir do Ubuntu. O primeiro destaca que não é por estarmos sempre em comunidade que não haja individualidade ou supressão das particularidades, mas que a finalidade das ações é coletiva. O segundo, aponta que não há o inanimado: aquilo que está presente no mundo contém uma força de maneira que se algo existe, então, vive e interfere no mundo. E o terceiro compreende que, quando alguém da comunidade fere a harmonia, este não deve permanecer recluso, pois, se assim acontecer, essa ferida atingirá aqueles que ainda nascerão. Diante disso, a ética Ubuntu consolida-se em lei, cuja evidência acontece pela temporalidade: "Uma dívida ou uma disputa não se extingue jamais até que restabeleça o equilíbrio, apesar de terem passadas várias gerações" (M'BAYE, 1974, p. 174).

Para ilustrar as possíveis cicatrizes que abalam a harmonia da comunidade, a aula teve como debate as diversas manifestações do 
racismo que, mesmo sob diferentes facetas, continua a desumanizar os povos africanos e da diáspora. Assim, a injustiça racial perdura na memória histórica dos prejudicados e não desaparece simplesmente com o passar do tempo. Por fim, o entendimento da turma com a exposição do Ubuntu é de que uma teoria ética não se limita ao antropocentrismo, mas agir eticamente significa interrogar sobre o ser humano e como a humanidade é uma composição de comunidades que precisa estabelecer um equilíbrio entre os diferentes modos de existência.

No $2^{\circ}$ ano do ensino médio na escola estadual em Colombo-PR, a prática pedagógica aqui relatada concentrou-se na categoria 30 "filosofia francesa contemporânea; Foucault; Deleuze" (BRASIL, 2003, p. 37). O ponto inicial questionava sobre de que maneira poderíamos aproximar a filosofia francesa e seus autores com a vivência da localidade da comunidade escolar; depois qual autor ou autora não ocidental poderia dialogar a partir dessas teorias. Frantz Fanon foi o autor elencado, uma vez que permite uma correlação entre Foucault e Deleuze através da sociedade disciplinar e da sociedade de controle, contribuindo, também, com o debate sobre sociedades colonizadas.

A sociedade disciplinar, descrita por Foucault, se destaca como diversas instituições na modernidade europeia que foram formadas com o propósito de disciplinar o corpo tornando-o dócil, por exemplo, em hospitais, escolas, quarteis, etc. "Pode-se então falar, em suma, da formação de uma sociedade disciplinar nesse movimento que vai das disciplinas fechadas, espécie de 'quarentena' social, até o mecanismo indefinidamente generalizável do 'panoptismo8"' (FOUCAULT, 2013, p. 204). A sociedade de controle, como observa Deleuze (1992), expande a disciplinar para o caráter da informação, pois pretende dispor a vigilância virtual dos corpos através de uma contínua monitoração: "Os confinamentos são moldes, distintas moldagens, mas os controles são uma modulação [...] ou como uma peneira

8 O Panóptico é uma figura arquitetural de Jeremy Bentham para locais de encarceramento. Foucault analisa o efeito de tal arquitetura como a indução no detento de um estado consciente e permanente de visibilidade, assegurando a manutenção do poder.

Revista Exitus, Santarém/PA, Vol. 9, № 4, p. 147 - 175, Out/Dez 2019. 
cujas malhas mudassem de um ponto a outro" (DELEUZE, 1992, p. 221). Sobre a sociedade colonizada, como analisa Fanon (2008), podemos dizer que ela não está além da sociedade disciplinar ou de controle, mas adentra na disciplina e no controle como maneira de dicotomizar os sujeitos. Com isso, a construção das cidades estratifica o centro e a periferia e imputa a imagem metropolitana nas mentes colonizadas:

O olhar que o colonizado lança sobre a cidade do colono é um olhar de luxúria, uma olhar de inveja. Sonhos de posse. Todos os modos de posse: sentar-se à mesa do colono, deitar-se na cama do colono, se possível com a mulher dele. O colonizado é um invejoso. $O$ colono não ignora isso e, surpreendendo o seu olhar vago, constata amargamente e sempre em alerta: 'Eles querem nosso lugar'. É verdade, não há um colonizado que não sonhe, ao menos uma vez por dia, instalar-se no lugar do colono (FANON, 2008, p. 56).

A partir da exposição desses três tipos de sociedades, o debate ampliou o olhar dos/as estudantes sobre os modos de pensar a cidade em que vivem, principalmente por haver uma idealização histórica na sociedade brasileira para aquelas pessoas de origem de países do Norte global, que idealizam um modelo de civilização em contrapartida àqueles do Sul. Inclusive, essa idealização acometeu a própria filosofia. Em decorrência desse debate em aula, uma pergunta se tornou frequente: "por que vemos poucos filósofos negros ou indígenas?". Então formulamos outra para reflexão: Como a nossa sociedade legitima um conhecimento exterior e não ouve as vozes daqueles que compõem a nossa sociedade?

Com essas perguntas, a experiência de uma descolonização curricular certifica que "decifrar" o conhecimento, seguido de um "alfabetismo da diáspora" são cruciais para uma metodologia que parte do território como modo de apresentar epistemologias produtoras de filosofias africanas. E com isso podemos analisar a lei 10.639/2003 e suas contribuições para inserção das falas daqueles/as que se encontravam silenciados. 


\section{CONSIDERAÇÕES FINAIS}

Se historicamente a escola, o currículo e a sala de aula contêm em si uma tensão de valores, ideologias, vivências e preconceitos, de maneira que a discriminação racial se apresenta como um fator da seletividade institucional escolar, as mudanças propiciadas por uma formação dirigida à reeducação das relações étnico-raciais pode interromper um processo educacional excludente.

É necessário, nesse sentido, enfrentar o silêncio que se impõe na diversidade de corpos, reconhecendo, a partir do que demonstra Gomes (2012, p. 105), que o "silêncio diz de algo que se sabe, mas não se quer falar ou é impedido de falar". Diante disso, a Lei $n^{\circ}$ 10.639/2003 torna-se um instrumento oficial que possibilita, através de novas narrativas do currículo, o rompimento com o silêncio e estimula a denúncia de atos favoráveis à discriminação racial. É o reconhecimento, a partir do que argumenta Marcos Ferraz (2013, p. 39), de que: "Não é por estar escrito na Lei que um direito se efetiva. Mas por estar na Lei, um direito abre o universo da reivindicação política".

Assim, os currículos escolares sofrem modificações estruturais a favor de uma educação antirracista por tornar público e legitimar a "fala" sobre questões afro-brasileiras e africanas:

\footnotetext{
Mas não é qualquer tipo de fala. É a fala pautada no diálogo intercultural. E não é qualquer diálogo intercultural. É aquele que se propõe ser emancipatório no interior da escola, ou seja, que pressupõe e considera a existência de um 'outro', conquanto sujeito ativo e concreto, com quem se fala e de quem se fala. E nesse sentido, incorpora conflitos, tensões e divergências (GOMES, 2012, p. 105).
}

Desse modo, os diferentes sujeitos com suas respectivas culturas no ato do diálogo e de interferência, influenciam na produção de novos projetos curriculares que não se assentam em nenhuma "harmonia", "quietude" ou "passividade", e sim no "reconhecimento da nossa igualdade enquanto seres humanos e sujeitos de direitos e da nossa diferença como sujeitos 
singulares em gênero, raça, idade, nível socioeconômico e tantos outros" (GOMES, 2012, p. 105).

Tal exercício, contudo, não se estabelece na valorização romantizada da semelhança, marginalizando o dessemelhante. É precisamente pelo requerimento de posições, diante das tensões acerca do currículo que a disciplina de Educação das Relações Étnico-Raciais nos cursos de licenciaturas, possibilita a compreensão de uma prática pedagógica que incita uma permanente reflexão sobre o currículo.

É ao menos o que se almeja a partir da obrigatoriedade de tal disciplina para os cursos de licenciatura (no caso da Ufes, por exemplo), em especial para o curso de Filosofia, aqui escolhido como alvo de análise, principalmente se outras vozes incitarem uma proposição curricular que demarque o território político e acadêmico das epistemologias africanas e afro-brasileiras.

\section{REFERÊNCIAS}

A NEGAÇÃO do Brasil (Documentário). Direção de Joel Zito Araújo. Casa da Criação: São Paulo, 2000. 1. DVD (92 min), color.

BENTO, M. A. S. Branqueamento e branquitude no Brasil. In: CARONE, I.;

BENTO, M. A. S. (Orgs). Psicologia social do racismo: estudos sobre branquitude e branqueamento. Petrópolis: Vozes, 2002. p. 25-58.

BRASIL. Orientações curriculares para o ensino médio: Ciências humanas e suas tecnologias. Secretaria de Educação Básica, v. 3, Brasília: Ministério da Educação, Secretaria de Educação Básica, 2006.

\section{BRASIL. Orientações Educacionais Complementares aos Parâmetros}

Curriculares Nacionais ( $\mathrm{PCN}+$ ): Ciências Humanas e suas tecnologias. Brasília: MEC, 2006.

BRASIL. Presidência da República. Lei 10.639 de 9 de janeiro de 2003(b). Altera a Lei n 9.394, de 20 de dezembro de 1996, que estabelece as diretrizes e bases da educação nacional, para incluir no currículo oficial da Rede de Ensino a obrigatoriedade da temática "História e Cultura AfroBrasileira", e dá outras providências. Diário Oficial da União. Brasília, DF, 10 jan. 2003, p. 1.

BRASIL. Resolução CNE/CP n $1^{\circ}$, de 17 de junho de 2004. Institui Diretrizes Curriculares Nacionais para a Educação das Relações Étnico-Raciais e para 
o Ensino de História e Cultura Afro-Brasileira e Africana. Diário Oficial da União, Brasília, DF, 22 jun. de 2004, Seção 1, p. 11.

CAVALLEIRO, E. Do silêncio do lar ao silêncio escolar: racismo, preconceito e discriminação na educação infantil. 5. ed., São Paulo: Contexto: 2006.

COELHO, M. C.; COELHO, W. N. B. As licenciaturas em história e a lei 10.639/03 - percursos de formação para o trato com a diferença?. Educ. rev., Belo Horizonte, v. 34, e192224, 2018.

CUNHA JÚNIOR, H. Nós, afrodescendentes: história africana e afrodescendentes na cultura brasileira. In: MINISTÉRIO DA EDUCAÇÃO E CULTURA. História da educação do negro e outras histórias. Brasilia: SECAD/MEC, 2005. p. 249-273.

DELEUZE, G. Post-scriptum sobre as sociedades de controle. Conversações: 1972-1990. Rio de Janeiro: Ed. 34, 1992.

ESPÍRITO SANTO. Currículo Básico Escola Estadual. Secretaria da Educação, v. 3, Vitória: SEDU, 2009.

FANON, F. Pele negra, máscaras brancas. Tradução de Renato de Silveira. Salvador: EDUFBA, 2008.

FERRAZ, M. Estado, sociabilidade e educação. In: GOUVEIA, A.; SOUZA, A.; TAVARES, T. (Orgs.). Políticas educacionais: conceitos e debates. Curitiba: Appris, 2013, p. 23-49.

FOUCAULT, M. Vigiar e Punir: o nascimento da prisão. Petrópolis: Editora Vozes, 2013.

GALLO, S. A Filosofia e seu ensino: conceito e transversalidade. Ethica. Rio de Janeiro, v. 13, n. 1, p. 17-35, 2006.

GOMES, N. L. Relações étnico-raciais, educação e descolonização dos currículos. Currículo sem Fronteiras, v.12, n.1, pp. 98-109, jan/abr 2012.

GOMES, N. L. Trajetórias escolares, corpo negro e cabelo crespo: reprodução de estereótipos ou ressignificação culturalẹ In: FÁVERO, Osmar; IRELAND, T. D. (Orgs.). Educação como exercício de diversidade. - Brasília: UNESCO, MEC, ANPEd, 2005 (Coleção Educação para todos, 7), p. 229-249.

JANZ, B. A Filosofia como se o lugar importasse: a situação da Filosofia Africana. In: GAMEZ, David; CAREL, Havi (Orgs.). Filosofia Contemporânea em Ação. Tradução de Fernando José R. da Rocha. Porto Alegre: Artmed, 2008.

KING, J. E. A Passagem Média revisitada: a educação para a liberdade humana e a crítica epistemológica feita pelos estudos negros. In: SILVA, L. E. 
(Org.). Reestruturação curricular: novos mapas culturais, novas perspectivas educacionais. Porto Alegre: Sulina, 1996. p. 75-101.

M'BAYE, K. The African Conception of Law. In: International Encyclopedia of Comparative Law, v. 2, 1974.

MACEDO, R. S. Currículo: campo, conceito e pesquisa. Petrópolis: Ed. Vozes, 2013.

MALDONADO-TORRES, N. A topologia do ser e a geopolítica do conhecimento. Modernidade, império e colonialidade. Revista Crítica de Ciências Sociais, 80, p. 71-114, mar/2008.

MBEMBE, A. Por que julgamos que a diferença seja um problema?. Deutsch Welle: Sprach, Kultur, Deutschland. 2016.

MILLS, C. The Racial Contract. Ithaca: Cornell University Press, 1997.

MUNANGA, K. Uma abordagem conceitual das noções de raça, racismo, identidade e etnia. In: BRANDÃO, André Augusto P. Programa de Educação sobre o negro na sociedade Brasileira (PNBES). Niterói: EdUFF, 2000.

(Cadernos PENESB, 5) p. 17-33.

NASCIMENTO, E. L. "Introdução às antigas civilizações africanas" E "As civilizações africanas no mundo antigo". In: NASCIMENTO, Elisa Larkin. (Org.). Sankofa I: a matriz africana no mundo. São Paulo: Selo Negro, 2008. (p. 55108).

NOGUEIRA, O. Preconceito racial de marca e preconceito racial de origem: sugestão de um quadro de referência para a interpretação do material sobre relações raciais no Brasil. Tempo Social, Revista de Sociologia da USP, p. 287-308, v. 19, n. 1, 2006 [1955].

NOGUERA, R. Denegrindo a filosofia: o pensamento como coreografia de pensamentos afroperspectivistas. Griot-Revista de Filosofia. Amargosa, Bahia-Brasil, v. 4, n. 2, p. 1-19, dez/2011.

OLIVEIRA, M. R. G. O diabo em forma de gente: (r)existências de gays afeminados, viados e bichas pretas na educação. 1. ed., Curitiba: Editora Prismas, 2017.

OYĚWÙMÍ, O. Conceituando o gênero: os fundamentos eurocêntricos dos conceitos feministas e o desafio das epistemologias africanas. African

Gender Scholarship: Concepts, Methodologies and Paradigms. CODESRIA Gender Series. v. 1, Dakar, CODESRIA, 2004, p. 1-8 por Juliana Araújo Lopes.

PANTERA Negra. Direção: Ryan Coogler. Marvel Studios: Burbank, CalifórniaEUA, 2018. 1. DVD (134 min), color. 
PARANÁ. Diretrizes Curriculares da Educação Básica - Filosofia. Curitiba:

Secretaria de Estado da Educação do Paraná, 2008.

RAMOSE, M. Sobre a Legitimidade e o Estudo da Filosofia Africana. Ensaios Filosóficos. v. 4, p. 6-25, out/2011,.

RAMOSE, M. The philosophy of ubuntu and ubuntu as a philosophy. In: COETZEE, P.H.; ROUX, A.J. (Org.) African Philosophy Reader. London:

Routledge, 2003.

SAPIÊNCIA, R. A coisa tá preta. In: Galanga Livre. Boia Fria Produções, São Paulo, 2017. Youtube. Disponível em:

https://www.youtube.com/watch?v=FsTTvHoLxEA. Acesso em 05 fev 2019.

SILVA, T. T. Documentos de identidade: uma introdução às teorias do currículo. Rio de Janeiro: Editora Autêntica, 2017.

SINGER, P. Ética prática. São Paulo: Ed. Martins Fontes, 2018.

THEODORO, M. A formação do mercado de trabalho e a questão racial no Brasil. In: THEODORO, M. (Org.). As políticas públicas e a desigualdade racial no Brasil: 120 anos após a abolição. Brasília: Ipea, 2008, p. 15-43.

VAN DIJK, T. Discurso e poder. São Paulo: Contexto, 2008.

Recebido em: 21 de fevereiro de 2019

Aprovado em: 30 de agosto de 2019 